\title{
BULLYING: NÃO SOFRA CALADO ${ }^{1}$
}

\author{
Leila Maria Almeida Rocha, UNR $^{2}$ \\ Maria dos Remédios Mendes Chaves Barreto, UNR ${ }^{3}$ \\ Anna Gabriella Silva Vaz Barreto, FAEME ${ }^{4}$ \\ Marília Princesa Guimarães Alves Mendes Barreto, UNIFSA ${ }^{5}$ \\ Leonar-Getúlio Segundo Alves Mendes Barreto, FAERPI ${ }^{6}$
}

\section{RESUMO}

A agressão acontece em todos os centros escolares com maior e menor intensidade, dessa forma, o interesse em representar o grande dano psicológico, social e físico para o aluno que o sofre, o exerce ou a presencia. Portanto é um fenômeno bastante complexo que requer estudo e reflexão. Esta pesquisa aborda a violência na escola e seus impactos na aprendizagem, tendo como objetivo geral: analisar o impacto da violência escolar no processo de ensino e aprendizagem e como objetivos específicos: entender de onde surge a violência na escola e identificar os principais tipos de violência presente no ambiente escolar. A metodologia foi baseada na pesquisa bibliográfica, de natureza qualitativa, com abordagem descritiva e explicativa. Percebemos que o Bullying é um tipo de violência bastante praticado no cotidiano escolar, assim faz-se necessário que os professores e os demais membros da instituição escolar busquem desenvolver programas e projetos para combater esse tipo de violência com o intuito de desenvolver uma educação de qualidade.

Palavras-chave: Bullying. Escola. Violência. Aprendizagem. Educação.

\footnotetext{
1 Trabalho apresentado no Congresso Brasileiro Ciência e Sociedade (CBCS 2019), promovido pelo Centro Universitário Santo Agostinho, de 03 a 05 de outubro de 2019, em Teresina-PI.

${ }^{2}$ Mestranda em Educação pela Universidade Nacional de Rosário - UNR - Argentina. Email:leilapsi_11@hotmail.com

3 Mestranda em Educação pela Universidade Nacional de Rosário - UNR - Argentina. Email:psic.remediosbarreto@hotmail.com

${ }^{4}$ Especialista em Atendimento Educacional Especializado (AEE) pela Faculdade Evangélica do Meio Norte (FAEME). Email: gabiwsg02@gmail.com

${ }^{5}$ Estudante de Psicologia da UNIFSA. Email: mariliaprin12@gmail.com

${ }^{6}$ Pedagogo pela Faculdade Entre Rios do Piauí-FAERPI. Email: leonargsamb@gmail.com
} 


\section{conghESSO CIENCIAESOCIEDADE \\ Inovaçãa, Diversidaade e Sustentahililitaile}

\section{INTRODUÇÃO}

Em diversos setores a violência é vista com destaque, no que se remete ao ambiente educacional não é diferente. Diariamente nas escolas de Ensino Fundamental essa prática é um dos motivos que acarreta resultados negativos em sala de aula e até mesmo na vida dos alunos e dos próprios professores. Para tanto esta pesquisa pautou-se sobre a violência na escola e seus impactos na aprendizagem.

É possível compreender que a violência é um fator que dificulta a prática docente, favorecendo um baixo rendimento educacional. $\mathrm{O}$ bullying pode ser considerado uma dessas práticas. O ambiente e o espaço que deveriam ser utilizados para o aprendizado e para trocas de experiências positivas acabam por ser alterados e desperdiçados por conta de agressões, interferindo diretamente no rendimento escolar dos alunos. Sendo assim, com o aumento da violência em suas diversas formas vem deixando o clima escolar cada vez mais conturbado.

A violência está presente no cotidiano escolar em forma de agressão verbal ou física, mas a certeza é de que os alunos que convivem com essas situações, não se encontram propícios a receberem uma educação tranquila e satisfatória. Assim estabeleceu-se o problema: Quais os impactos da violência escolar no processo de ensino e aprendizagem?

Para Lima (2007), o bullying é um tipo de violência presente no ambiente escolar. Compreender como a violência nas escolas afeta o processo de ensinoaprendizagem é um fator de suma importância na formação do pedagogo, como profissional. Nesse sentido podemos salientar que profissionais da pedagogia possuem um importante papel na erradicação da violência na escola. O pedagogo não é o responsável por tratar estas falhas, que não são apenas educacionais, mas principalmente, sociais, destacamos sua grande importância na elaboração de projetos que visem minimizar fatores de violência dentro da sala de aula.

Para diminuir essa violência na escola é necessário, antes de tudo, compreender de onde parte os atos infratores e por qual motivo estes surgem, dessa maneira será possível desenvolver uma aprendizagem eficaz. 


\section{CONQEEESSOCIENCIAESOCIEDADE

Ao escolher este tema buscamos como objetivo geral: analisar o impacto da violência escolar no processo de ensino e aprendizagem e como objetivos específicos: entender de onde surge a violência na escola e identificar os principais tipos de violência presente no ambiente escolar.

A metodologia desta pesquisa foi baseada na pesquisa bibliografia, de natureza qualitativa e abordagem descritiva e explicativa. "A pesquisa bibliográfica é desenvolvida com base em material já elaborado constituído principalmente de livros, revistas, artigos científicos". (GIL, 2002, p.44).

Alguns estudos mostram que nos últimos anos a violência praticada por crianças no ambiente escolar aumentou significativamente, por essas e outras razões que os professores e demais membros da escola buscam compreender a dimensão que a violência apresenta que, entretanto, é importante que os responsáveis saibam estabelecer metas e formas para tentar diminuir este problema que é a violência no âmbito escolar.

\section{A VIOLÊNCIA NA ESCOLA}

Entender conceitos e prerrogativas acerca de violência por estudiosos faz com que o embasamento teórico se fortaleça e soluções para diminuir o problema sejam mais facilmente elaboradas.

O autor Raymundo de Lima (2007), no texto "Violência na/da Escola", faz uma reflexão sobre como uma criança pode conseguir concretizar o aprendizado após ter sido vítima da violência. Não importando o formato desta violência, seja ela verbal ou física, no momento deste ato há uma desestruturação emocional que atinge todo o sistema nervoso do indivíduo. Assim, "[...] a violência gera sofrimento, causa danos físicos e psicológicos, humilhação, desespero, desamparo, desesperança e anuncia a barbárie onde todos podem ser vítimas". (LIMA, 2007, p. 65). Certamente, todos os profissionais envolvidos nesta escola, ficam com o psicológico abalado, mas os mais atingidos são os alunos. 


\section{CONQEEESSOCIENCIAESOCIEDADE

É importância salientar que a violência escolar está presente, entretanto faz- se necessário que os professores busquem meios e formas para combater os diversos tipos de violências.

A violência pode surgir quando os alunos não são respeitados como pessoas e seres individuais. Os alunados por sua vez, tendem a responder por meio da indisciplina ao seu professor. As más formações dos professores também podem prejudicar a qualidade do trabalho desenvolvido em sala de aula, local no qual existe falta de motivação causada pela desvalorização dos profissionais do magistério.

É nesse sentido que a violência aparece como elemento prejudicial para a qualidade de ensino. Para Silva (2009) o atual currículo escolar não acompanha as realidades dos estudantes, já que estes não se reconhecem dentro do contexto que Ihes são expostos. Isso gera inquietação, falta de interesse e, além disso, o aprendizado não se concretiza. Silva, afirma: “[...] o conteúdo programático da maioria das escolas apresenta-se desvinculado da realidade sendo quase inaplicável no contexto social". O mesmo se pode afirmar do sistema de normas e regulamentos e dos projetos político-pedagógicos (SILVA, 2009, p. 3).

É fato que a escola vive um momento de crise, que possui várias formas de manifestação, uma delas é a violência no seu interior. É como se ela tivesse perdido seu referencial, “[...] é que a escola parou no tempo e não incorporou no seu cotidiano tecnologias e conteúdos a que os alunos têm tido acesso" (SILVA, 2009, p. 5).

Nesta dimensão é possível dizer que a escola, é uma instituição que forma cidadão, no entanto a mesma enfrenta diversas barreiras, e uma delas é a violência, onde se faz necessário que os membros da instituição estejam atentos para tentar solucionar os problemas que venham a surgir na escola. Charlot (2002) conclui que a escola é um ambiente de tensão, que é gerada fora dela, ou seja, contendo os problemas familiares e da sociedade como uma das principais causas.

Para Madeira (2000, p. 16), “Os jovens pobres e ricos desejam uma escola onde consigam aprender, mas que também seja um espaço agradável, onde possam encontrar amigos, ouvir músicas e namorar". Alguns professores tendem a olhar para 


\section{CONQEEESSOCIENCIAESOCIEDADE

o jovem violento como delinquente e ou marginal e, principalmente, os pobres serão por vezes vistos como tais.

Este ambiente então não fará nenhum sentido para ele, assim, as “[...] tensões e os conflitos tendem a se acentuar ampliando o fosso dos desencontros entre alunos e professores" (MADEIRA, 2000, p.15).

Para Madeira (2000), a mídia não apenas notícia os acontecimentos que ocorrem nas escolas, ao intensificar os casos de violência, ela motiva e encoraja os jovens a praticá-los com mais frequência, pois aparecerão no noticiário e estarão em evidência para os colegas e para a comunidade.

Enquanto os professores ao constatarem a extensão do problema, entram em estado desconfortável de tensão. Madeira (2000, p. 3) assim se expressa: “[...] atos de criminalidade praticados por adolescentes e muito veiculados pela mídia são especialmente propícios para gerar representações sociais que criam ou fortalecem um clima de pânico social." É a própria escola e seus integrantes que ficam sem norte para seguirem com o mesmo processo pedagógico, é neste momento em que se perdem e o caos toma conta da instituição.

\section{O BULLYING}

Segundo Lins (2010, p. 13) o bullying passou a ser considerado como "problema de saúde pública", entretanto é um problema presente nas escolas, em razão disso são necessários profissionais especializados na área para agirem em conjunto com os profissionais do ambiente perturbado. O bullying também pode agravar problemas preexistentes, devido ao tempo prolongado de estresse a que a vítima é submetida. Em casos mais graves, podem-se observar quadros de esquizofrenia, homicídio e suicídio (SILVA, 2009), assim como deixa o aluno sem vontade de participar das atividades escolares.

Lins (2010) enfatiza que: 
Sintomas psicossomáticos: cefaleia, cansaço crônico, insônia, dificuldades de concentração, náuseas, diarreia, boca seca, palpitações, alergias, crises de asma, sudorese, tonturas, tensão muscular entre outras; - Transtorno do pânico: caracteriza-se por medo intenso, infundado e sem motivo aparente, acompanhado de grande ansiedade e de uma série de sintomas físicos; - Fobia escolar: caracterizada pelo medo intenso de frequentar a escola o que resulta em repetências por faltas, dificuldades de aprendizagem e evasão escolar; - Fobia social ou transtorno de ansiedade social (TAS): também conhecida por timidez patológica, entre outros (LINS, 2010, p.11).

Podemos constatar que o bullying é causado por vários sintomas nesta dimensão é fundamental que os professores estejam sempre atentos, pois o bullying afeta bastante o desenvolvimento no processo de ensino e aprendizagem, no contexto escolar.

O bullying é algo sério e não deve ser visto como uma brincadeira, a criança que sofre bullying sentirá insegurança, medo, dentre outros aspectos semelhantes, assim dificultando o desenvolvimento do processo de ensino e aprendizagem. Para se tentar solucionar esse problema pensa-se que, “[...] O bullying nas escolas, poderá alcançar um envolvimento ativo por parte dos professores e dos pais, aumentar a conscientização do problema para eliminar mitos sobre o bullying e prover apoio e proteção às vítimas". (FANTE, 2010 p. 3).

Podemos entender que Bullying são todos os tipos de violências praticadas na escola, assim dificultando a aprendizagem do indivíduo, por tanto é importante que os professores estejam atentos às mudanças de comportamento de seus alunos. Entendemos que o Bullying é considerado um conjunto de agressões, praticada de forma direta e indireta, muitas vezes acontece sem motivo, deixando a vítima com autoestima baixa, insegura e que essa consequência atrapalhará a sua vida pessoal e profissional.

Compreende todas as atividades agressivas intencionais e repetitivas, que ocorrem sem motivação evidente, adotadas por um ou mais estudantes contra outro(s), causando dor e angústia, sendo executados dentro de uma relação desigual de poder. Essa assimetria de poder associada ao bullying pode ser consequente da diferença de 


\title{
CONGERESSOCIENCIAESOCIEDADE \\ Inovação, Diversidaale e Sustentahilitilade
}

idade, tamanho, desenvolvimento físico ou emocional, ou do maior apoio dos demais estudantes (LOPES NETO, 2005, p.165).

O comportamento agressivo intencional que pode se expressar de diversas maneiras (verbal, física, social e emocionalmente; em relacionamentos, pela internet, ou numa combinação de vários desses fatores). O Bullying é visto como uma atividade hostil que é praticada com o desejo de ferir, machucar a vítima, esse fenômeno sempre está associado a quatro elementos: o desequilíbrio, poder, intenção e ameaça.

\section{AS VÁRIAS FORMAS DE BULLYING}

O Bullying é considerado um fenômeno no ambiente escolar, que se faz necessário, uma intervenção mesmo que não venha a solucionar, mas que possa diminuir esse tipo de violência no ambiente escolar.

\begin{abstract}
Uma das formas de violência escolar, que tem merecido grande atenção por parte de pesquisadores nas últimas décadas, tem sido denominada, na literatura internacional, como bullying. É uma forma de violência frequente ocorrida entre colegas na escola. (PINHEIRO, 2006. p. 4)
\end{abstract}

É possível analisar que as formas de violência na escola, merece uma atenção especial de que forma isso pode ser através da criação de programas, palestras, não somente por parte da escola mais toda equipe responsável pelo o desenvolvimento educacional, com relação ao Bullying alguns pesquisadores denominaram o mesmo como uma violência que oferece graves consequências [...] o bullying é considerado quando "um estudante está sendo vitimado, quando é exposto repetidamente e por um tempo prolongado, a ações negativas por parte de um ou mais estudantes" (OLWEUS, 1999, p.10). Além dos termos utilizados podem se classificar também como Bullying agredir, vitimar, violentar, maltratar, humilhar, intimidar e chatear. (PEREIRA, 2008, p.24).

Diante disso compreendemos que são várias as formas de Bullying presente no contexto escolar, quanto às formas de agressão mais utilizadas, "podem ser sistematizadas em três formas fundamentais: a agressão física, a agressão direta verbal 
e a agressão indireta". (PEREIRA, 2008, p.51). Podemos salientar que existem diversas formas de se praticar o Bullying cada uma mais violenta do que a outra, em muitas situações a vítima não tem como se defender das ofensas praticadas pelo agressor.

Todas as formas de atitudes agressivas, intencionais e repetidas que ocorrem sem motivação evidente, adotadas por um ou mais estudantes contra outro (s), causando dor e angústia, e executadas dentro de uma relação desigual de poder. Portanto, os atos repetidos entre iguais (estudantes) e o desequilíbrio de poder são as características essenciais, que tornam possível a intimidação da vítima. Todas as formas de atitudes agressivas, intencionais e repetidas que ocorrem sem motivação evidente, adotadas por um ou mais estudantes contra outro (s), causando dor e angústia, e executadas dentro de uma relação desigual de poder. Portanto, os atos repetidos entre iguais (estudantes) e o desequilíbrio de poder são as características essenciais, que tornam possível a intimidação da vítima. (PEREIRA, 2008, p.05).

Considerando, o Bullying como fenômeno constantemente presente no âmbito escolar, sabemos que todas as formas que se pratica o Bullying são de atitudes agressivas, que acontece sem nenhuma motivação, mas que o agressor tem o prazer de praticar, deixando a vítima sem chance de defesa.

\section{AS VÍTIMAS DE BULLYING}

As vítimas de Bullying na escola sofrem graves consequências, muitas delas não conseguem se inserir no contexto social, assim entendemos que essas vítimas necessitam de um acompanhamento psicológico, que as famílias busquem ajuda para solucionar este problema.

As vítimas típicas são os alunos que apresentam pouca habilidade de socialização. Em geral são tímidas ou reservadas, e não conseguem reagir aos comportamentos provocadores e agressivos dirigidos contra elas. Normalmente são mais frágeis fisicamente ou apresentam alguma marca que as destaca da maioria dos alunos [...]. (SILVA, 2009, p. 38).

De acordo com esse autor, percebemos que as vítimas de Bullying geralmente são alunos que apresentam dificuldades em socialização com os outros, são pessoas mais reservadas, não se envolve nas atividades em sala de aula etc. "É fundamental 


\section{CONQEESSOC CIENCIAESOCIEDADE \\ Inovação, Diversidaale e Sustentahilitilade}

explicar que as atitudes tomadas por um ou mais agressores contra um ou alguns estudantes, geralmente, não apresentam motivações específicas ou justificáveis" (SILVA, 2009, p. 21).

As consequências do Bullying são gravíssimas, é de grande importância compreender que as atitudes tomadas por parte do agressor geralmente é atacar as crianças mais frágeis, as agressões em alguns casos acontecem sem motivo, assim digamos que os agressores sentem prazer em amedrontar suas vítimas.

O Bullying é considerado os fenômenos presentes no ambiente em razão disso os professores precisam buscar compreender como se manifesta, e quando identificar a vítima desse tipo de violência é indispensável a comunicação da família, acredita-se que a família e escola deverá buscar solucionar este problema juntos. Por parte dos agressores "as consequências podem vitimá-las no futuro, de acordo com o rumo que sua vida tomar" (MELO, 2010, p.42).

Faz-se compreender que as vítimas de Bullying sofrem as consequências na vida seja no ambiente pessoal como profissional, as vítimas são frágeis fisicamente apresentam manchas na pele são magras, baixas, "as vítimas são alunas gordinhas ou magras, altas ou baixas, com manchas na pele, orelhas ou nariz um pouco mais destacados; usam roupa fora de moda; são de raça, credo, condição socioeconômica ou orientação sexual diferente" (SILVA, 2009, p.37).

De acordo com Santana (2011, p.35) "a vítima, têm dificuldade de concentração nas aulas, baixo rendimento escolar, depressão, síndrome do pânico e sentimento de culpa por ter problemas ou dificuldades". Entretanto a vítima de Bullying terá dificuldades de socialização, não tem um rendimento no desenvolvimento do processo educacional. As vítimas de Bullying são consideradas as crianças mais frágeis com dificuldades de aprendizagem, daí é importância de que a escola busque desenvolver palestras, diálogo mostrando o que o Bullying traz de consequências para a vida de uma criança.

\section{CONSIDERAÇÕES FINAIS}


Sabemos que o Bullying está constantemente presente no ambiente escolar, no entanto se faz necessário que os professores e demais envolvidos no processo de ensino e aprendizagem busquem conhecer o que é Bullying, tendo como eles os mediadores do conhecimento possam interferir no combate a violência na escola.

No decorrer deste estudo percebemos que a educação enfrenta diversos desafios que, a escola está sempre preocupada com o processo de ensino e aprendizagem dos alunos, por essas e outras razões estão sempre inovando e renovando as metodologias de ensino, a elaboração de programas para que se possam alcançar os objetivos educacionais.

Por tanto entendemos que o Bullyung é considerado um grande fenômeno, no contexto escolar, esse tipo de violência traz graves consequências para a vida de alunos que sofrem Bullying, geralmente as vítimas são aquelas crianças que não conseguem desenvolver uma boa relação com as outras. Nesse sentido podemos salientar que o professor enquanto principal sujeito responsável pelo o processo de ensino e aprendizagem em sala de aula devem buscar meios, metas que viabilizem a criação de projetos de combate à violência podendo contribuir para a sensibilização dos estudantes e fazer com que suas atitudes possam mudar, proporcionando um melhor clima escolar.

\section{ABSTRACT}

Aggression occurs in all schools with higher and lower intensity and claims the interest for how much it can represent great psychological, social and physical damage to the student who suffers, exercises or witnesses. Therefore it is a very complex phenomenon that requires study and reflection. This research addresses school violence and its impacts on learning, having as its general objective: to analyze the impact of school violence on the teaching and learning process and as specific objectives: to understand where school violence comes from and to identify the main types of violence. Present in the school environment. The methodology was based on bibliographic research, qualitative in nature, with descriptive and explanatory approach. We realize that bullying is a type of violence that is widely practiced in daily school life, so it is necessary that teachers and other members of the school institution seek to develop programs and projects to combat this type of violence in order to develop quality education. 


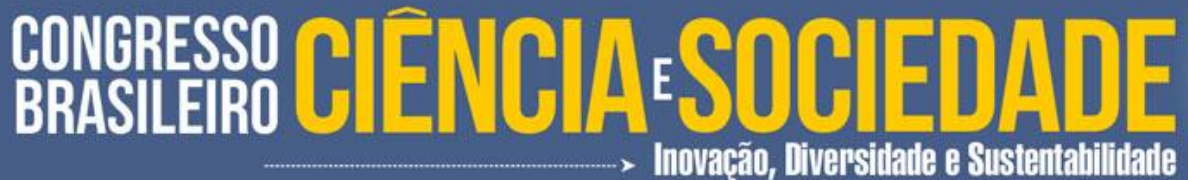

Keywords: Bullying. School. Violence. Learning. Education.

\section{REFERÊNCIAS}

CHARLOT, B. A violência na escola: como os sociólogos franceses abordam esta questão. Sociologias, Porto Alegre, 2002.

FANTE, Cléo. Fenômeno bullying: como prevenir a violência nas escolas e educar para a paz. 2. ed. rev. e ampla. Campinas, SP: Verso, 2010.

GIL, Antônio Carlos. Didática do ensino superior, como elaborar projeto de pesquisa.4.ed. São Paulo,2002.

LIMA, R. de. Violência na/da escola. Revista Espaço Acadêmico. N 78, mensal, ano VII, nov.2007.

LINS, R. C. B. S. Bullying: Que fenômeno é esse? Rev. Pedag. vol. Inaugural, 2010.

MADEIRA, R. Violência nas escolas quando a vítima é o processo pedagógico. SEADE: São Paulo em perspectiva: a violência disseminada, 2000.

MELO, Josivaldo Araújo de.Bullying na escola: como identificá-lo, como preveni-lo, como combatê-lo;Recife: EDUPE, 2010.

MOURA, Danilo Rolim de. Prevalência e características de escolares vítimas de bullying.J. Pediatr. (Rio J.), 2011.

OLWEUS, D. Prevalenceandincidenteestudyof anti-social behavior: Definitions and measurement. In, M. Klein (ed). Cross.national research in self-reportd crime anddelinquency.Dordrecht, The Netherlands, Kluwer, 1999.

PEREIRA, Beatriz Oliveira. Para uma escola sem violência - estudo e prevenção das práticas agressivas entre crianças. Lisboa: Dinalivro. 2008.

PINHEIRO, F. M. F. Violência intrafamiliar e envolvimento em "bullying" no ensino fundamental. Dissertação de Mestrado. Universidade Federal de São Carlos: UFSCar, 2006.

SANTANA, Edésio T. Bullying e Cyberbullying Agressões presenciais e a distância o que os educadores e os pais devem saber São Paulo: EDICON, 2011.

SILVA, G. J. Bullying: quando a escola não é um paraíso.Ed. Mundo jov. 2010. 